\title{
BMJ Open Objectively assessed physical activity patterns and physical function in community-dwelling older adults: a cross-sectional study in Taiwan
}

\author{
Ming-Chun Hsueh (D) , ${ }^{1}$ Ru Rutherford (D) , ${ }^{2}$ Chien-Chih Chou, ${ }^{1}$ Jong-Hwan Park, ${ }^{3}$ \\ Hyun-Tae Park, ${ }^{4,5}$ Yung Liao (1) ${ }^{2}$
}

To cite: Hsueh M-C,

Rutherford R, Chou C-C, et al. Objectively assessed physical activity patterns and physical function in community-dwelling older adults: a cross-sectional study in Taiwan. BMJ Open 2020;10:e034645. doi:10.1136/ bmjopen-2019-034645

- Prepublication history and additional material for this paper are available online. To view these files, please visit the journal online (http://dx.doi. org/10.1136/bmjopen-2019034645).

C-CC and J-HP contributed equally.

Received 02 October 2019 Revised 24 June 2020 Accepted 02 July 2020

Check for updates

(c) Author(s) (or their employer(s)) 2020. Re-use permitted under CC BY-NC. No commercial re-use. See rights and permissions. Published by BMJ.

For numbered affiliations see end of article.

Correspondence to Professor Chien-Chih Chou; ccc4453@gmail.com

\section{ABSTRACT}

Objectives To objectively assess light physical activity (PA), moderate-to-vigorous PA (MVPA), step counts and number of 10 min MVPA bouts and their association with physical function among older adults.

Design Cross-sectional design.

Setting Urban community setting in Taiwan.

Participants 127 Taiwanese older adults aged over 65 years (mean age $=70.8 \pm 5.3$ years; $72 \%$ women).

Primary and secondary outcome measures Triaxial accelerometers were used to measure PA variables for 10 hours/day for seven consecutive days. Then, five physical function components (handgrip strength, singleleg stance, 5-metre walk speed, timed up and go and sitto-stand test) were measured. Multiple linear regressions were used to perform separate analyses for older men and women.

Results For older women, daily MVPA time ( $\beta$ : 0.39 , $95 \% \mathrm{Cl}: 0.12,0.64 ; p=0.004)$, daily step counts ( $\beta$ : 0.46 , $95 \% \mathrm{Cl}: 0.12,0.78 ; p=0.009$ ) and number of $10 \mathrm{~min}$ MVPA bouts ( $\beta$ : $0.27,95 \% \mathrm{Cl}: 0.001,0.53 ; p=0.049$ ) were positively associated with handgrip strength after adjusting for accelerometer wear time, sedentary time and other confounders. Furthermore, daily MVPA time was positively associated with a single-leg stance ( $\beta$ : 0.25 , $95 \% \mathrm{Cl}: 0.02,0.49 ; \mathrm{p}=0.036$ ) and higher daily step counts were associated with shorter walking speed performance ( $\beta$ : $-0.31,95 \% \mathrm{Cl}:-0.57,-0.001 ; p=0.049$ ). None of the variables of the objectively assessed PA patterns was associated with physical function outcomes among older men due to their small sample size.

Conclusions Daily MVPA, MVPA bouts of at least $10 \mathrm{~min}$ and accumulated daily steps are important for improving physical function among older women. Future prospective research should establish causal associations between PA patterns and functional ability among older adults.

\section{INTRODUCTION}

Physical function (including mobility, muscle strength and standing balance) is an essential element in determining how older adults manage their daily errands and remain independent. ${ }^{1}$ Evidence indicates a causal pathway from a reduction of the physical function to disability because a limited physical function
Strengths and limitations of this study

- This is the first study to focus on physical activity (PA) patterns (specific-intensity PA, waking steps, 10 min moderate-to-vigorous PA bouts) related to physical function among older adults in Taiwan.

- Objective methods were used to assess PA patterns and physical functional components (mobility, muscle strength and standing balance) of older adults living in the community.

- The results were adjusted for multiple confounding variables, including accelerometer wear time and sedentary time.

- The sample size was relatively small.

contributes to negative health consequences, such as increased fall risk and physical frailty. ${ }^{2}$ Taiwan had approximately $14.56 \%$ (3 433517 ) people aged over 65 at the end of 2018, which is one of the fastest ageing rates in Asia. ${ }^{3}$ In comparison to the rest of the globe, the prevalence of disability among older Taiwanese adults is increasing. Approximately $12.7 \%$ of the older Taiwanese population has a disability. ${ }^{4}$ Therefore, given the importance of facilitating independence among Taiwanese older adults, deciphering strategies to improve physical function is a crucial target in designing interventions to prevent and mitigate disability in later life.

Many epidemiological studies have shown that daily physical activity (PA) positively affects physical function in older adults. ${ }^{56}$ The health policy in Taiwan instructs older adults to engage in at least $150 \mathrm{~min}$ of moderateto-vigorous PA (MVPA) each week as recommended by the WHO. ${ }^{7}$ A previous study also recommended that older adults should engage in at least $300 \mathrm{~min}$ of light PA (LPA) weekly. ${ }^{8}$ However, previous studies examining the associations between PA and physical function had limitations in several crucial aspects. 
First, despite the benefits of MVPA for physical function in older adults, ${ }^{910}$ the proportion of older adults meeting the recommended MVPA guidelines was low, and rapid ageing further intensified the challenge. ${ }^{11}$ Furthermore, a previous study indicated that pursuing LPA may be beneficial for health outcomes ${ }^{8}$ such as lower-extremity performance $^{12}{ }^{13}$; however, it is unclear whether the amount of LPA is associated with other physical function components (upper and lower body strength, balance and mobility). Moreover, the current international guidelines emphasise specific PA patterns ${ }^{7}$; for example, long bouts of MVPA (lasting at least $10 \mathrm{~min}$ ) are considered beneficial for the fulfilment of the MVPA guidelines and substantial health outcomes. ${ }^{14}$ Furthermore, daily walking steps have benefits for older adults' health ${ }^{15} 16$ and physical function. ${ }^{17}$ However, to our knowledge, no study has simultaneously examined the independent contributions of daily specific-intensity PA duration, 10 min MVPA bouts and walking steps to physical function. This information can aid the development of tailored PA programmes that can be incorporated into older adults' daily lives.

Second, most of the existing evidence either provides a limited explanation of the association of PA with physical function owing to the use of self-report data of exposures, outcomes or both, ${ }^{12}$ or limited information on overall physical function score. ${ }^{10}{ }^{18}$ Although some studies have objectively assessed PA and physical function in older adults, ${ }^{18} 19$ these studies did not adjust for accelerometer wear time, a key confounding factor. ${ }^{20}{ }^{21}$ Concerning accelerometers, factors such as wear time and sedentary time could partly confound the associations between PA and health outcomes. ${ }^{20-22}$ Therefore, it is imperative to study health risks inducing maximal adjustments for potential confounders. Another important research gap is that while PA levels and physical characteristics have been found to vary by gender, ${ }^{1323}$ few studies have separately identified the associations between $\mathrm{PA}$ and physical function by gender. ${ }^{10}{ }^{19}$ To our knowledge, no study has investigated the relationships of objectively assessed PA with physical function in Taiwan. Though the relationship between objectively assessed PA and physical function is evident in the USA ${ }^{24} 25$ and other western countries, ${ }^{19}$ it might vary according to different cultures and environments such as Taiwan, which has a high population density and where most people use public transportation. ${ }^{26}$ To address the problems associated with Taiwan's rapidly ageing population and address the aforementioned research gap, we aimed to examine objectively assessed PA patterns (specific intensity, $10 \mathrm{~min}$ MVPA bouts, daily step counts) and physical function in the older Taiwanese population.

\section{METHODS}

\section{Participants}

A cross-sectional study was conducted from April to September 2018. Data were collected from older men and women (65-87 years old) who lived in the community of Taipei City, Taiwan, and could walk independently. Detailed information on Taipei City and the procedure of recruitment were reported elsewhere. ${ }^{27}$ Participants were recruited through local advertisements and neighbourhood broadcasts. Interested individuals contacted the recruiters or neighbourhood representatives.

First, a structured questionnaire, including questions on demography, lifestyle behaviours and presence/absence of chronic diseases, was administered to each participant by trained interviewers. Furthermore, each participant underwent a physical function test (interpretation later). Then, participants were asked to wear an accelerometer (wGT3X-BT, ActiGraph, LLC, Pensacola, FL, USA) on the right side of their waist for seven consecutive days. ${ }^{28}$ Every participant who completed the questionnaire, physical function tests and the accelerometer portion of this study received a convenience store voucher worth US $\$ 7$.

In all, 170 participants completed the questionnaire and underwent the on-site examination of physical function by a team of trained research assistants. Of these, 22 participants declined to wear the accelerometer. Therefore, 148 participants were engaged in an on-site examination and wore an accelerometer for 7 days. Thereafter, incomplete or missing data on sociodemographic variables and/or physical performance were excluded $(n=21)$. Ultimately, 127 participants were included in the analysis. Figure 1 presents a flow diagram of the study recruitment process.

\section{Patient and public involvement}

No patient was involved in the design or conduction of this community-based cross-sectional study. The public was not involved in the study design or recruitment. Older adults consented to participate, knowing that they would receive their summary health report after the assessment visit.

\section{Measures}

\section{PA and procedures}

PA was measured with ActiGraph monitors (wGT3X-BT). The validity of this device for the measurement of PA in samples of older adults has been established. ${ }^{29}$ The participants were asked to wear the accelerometer on the right side of their waist, positioned above the right hip. ${ }^{28}$ Each participant personally received the device and an explanation regarding its use. Raw data collected from the movements registered on the vertical axis were divided into $60 \mathrm{~s}$ timeframes. ${ }^{28}$ Participants were asked to remove the device before showering or swimming. Additionally, we provided a diary to each participant and asked them to report their daily bedtime and waking time, and record when and why the wGT3X-BT accelerometer was removed. Then, we coded the sleep duration through each participant's sleep onset and offset times, and used algorithms built into the ActiLife software.$^{30}$ Finally, we categorised sleeping time as non-wear time. Non-wear time was described as periods of 60 or more continuous minutes of zero counts (indicating no lateral movement). ${ }^{28}$ The accelerometer data were considered valid for a minimum of 4 days (3 weekdays and 
218 potential subjects randomly recruited from neighbourhoods

170 potential participants completed self-

19 residents declined the on-site examination.

29 residents did not meet the inclusion criteria:

(1) age was less than 60 years $(n=24)$

(2) unable to walk independently $(\mathrm{n}=5)$ administered questionnaires

22 residents declined to wear the accelerometer

\section{8 residents participated in an on-site} examination and wore an accelerometer for 7

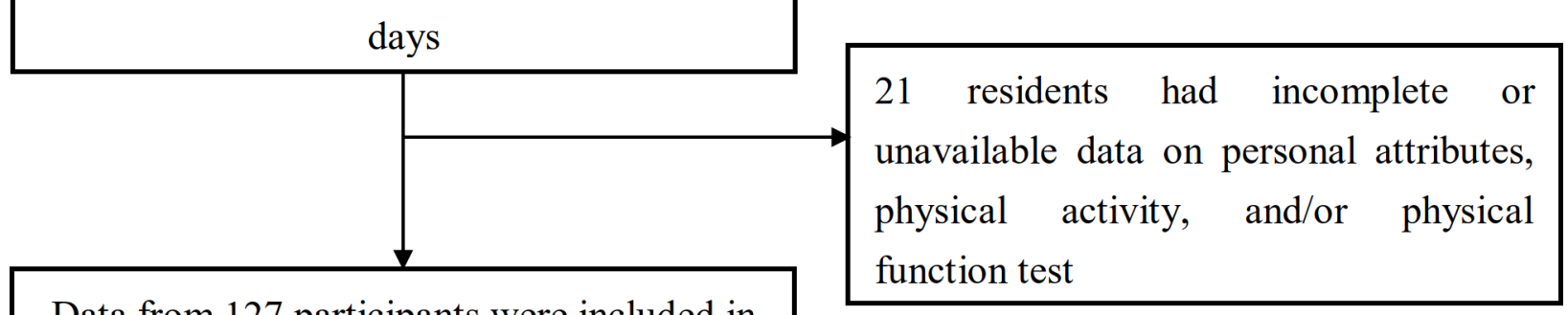
the analysis

Figure 1 Flow of Participants in this Study.

Figure 1 The flow of participants in this study.

1 weekend day), and at least $\geq 10$ hours of each day were recorded for analysis. ${ }^{28} 29$

The basic definition of PA was $\geq 100$ counts $/ \mathrm{min}$, with further differentiation to identify LPA (100-2019 counts/ min), MVPA ( $\geq 2020$ counts/min) and the number of $10 \mathrm{~min}$ MVPA bouts (defined as at least $10 \mathrm{~min}$ where the accelerometer registered $\geq 2020$ counts $/ \mathrm{min}$ ). ${ }^{31}$ The number of $10 \mathrm{~min}$ MVPA bouts was the smallest unit considered to contribute adequately to the recommended 30 min on most days. ${ }^{32}$

\section{Physical function}

Physical function was assessed according to five specified measures, including handgrip strength (upper body strength), single-leg stance test (standing balance), 5-metre walk test, timed up and go test (mobility) and sit-to-stand test (lower body strength), which have been validated for physical function evaluation in an older population. ${ }^{33}$ The procedures followed for each test were as follows:

\section{Handgrip strength}

Handgrip strength was measured in kilograms using the Jamar Plus+Digital Hand Dynamometer (Lafayette Instrument Company, Lafayette, IN, USA). The participants were instructed to sit on a straight-back chair and hold the device in both hands with arms parallel to the body. ${ }^{34}$ Then, the participants were asked to squeeze the dynamometer using maximum force. Each participant was asked to perform this action three times with a 1 min gap between attempts, and the best performance was used in the analysis. This test is a valid and reliable way to assess handgrip strength in older adults. ${ }^{35}$

\section{Single-leg stance test}

This test performed with eyes open is a valid assessment of standing balance function. ${ }^{36} \mathrm{~A}$ timer was used to record the time until participants lost their balance or reached a maximum of $60 \mathrm{~s}$. Participants were asked to perform two trials, and the better performance was used in the analysis. 


\section{5-Metre walk test}

This test, which measures gait speed, involves the individual walking $5 \mathrm{~m}$ in the middle of an 11-metre course at his or her fastest pace. The initial and final $3 \mathrm{~m}$ allow for acceleration and deceleration, respectively. Each participant was asked to perform one trial. The 5-metre walk test is a reliable and valid indicator of mobility function in older adults. ${ }^{37}$

\section{Timed up and go test}

This test measures the ability to walk with a dynamic balance. ${ }^{38}$ We instructed the participants to get up from a standard chair and then pace for a distance of $3 \mathrm{~m}$, return to the chair and sit down as fast as they could. The participants were asked to perform two trials, and the fastest time was used in the analysis.

\section{Sit-to-stand test}

The test is used to evaluate lower-limb functional strength. ${ }^{39}$ Participants were asked to rise from the chair (46 cm high and armless) to a full standing position and then return to a seated position as quickly as possible for five repetitions. The total time taken for five repetitions was calculated for our analysis.

\section{Covariates}

We used interviewer-administered questionnaires to assess the covariates, which included sociodemographic characteristics and health status, based on previous studies. ${ }^{5} 23$ The covariates were age, marital status (married or unmarried), living status (alone or with others), educational level (university or up to high school), job status (full time or part time), smoking status, alcohol consumption, healthy diet status, hypertension status, blood lipid levels, diabetes status, depression status and body mass index (BMI). BMI was calculated using self-reported weight and height, and was categorised into normal weight $(<24 \mathrm{~kg} /$ $\left.\mathrm{m}^{2}\right)$ and overweight $\left(\geq 24 \mathrm{~kg} / \mathrm{m}^{2}\right)$, based on the recommendations for the Asian population. ${ }^{40}$ Moreover, sedentary time and accelerometer wear time were included as covariates as they could confound the analysis of PA and health outcomes in older adults. ${ }^{2122}$

\section{Statistical analyses}

The analysis included data of 127 participants. The $\chi^{2}$ test and an independent t-test were used for proportional and continuous variables, respectively. Significant interactions were observed between gender and each of the accelerometer's PA variables: total PA time $(F=4.466, \mathrm{p}=0.037)$, daily LPA time $(F=11.645, \mathrm{p}=0.001)$, daily MVPA time $(F=15.979, \mathrm{p}=0.001)$, daily step counts $(F=4.056, \mathrm{p}=0.046)$ and number of $10 \mathrm{~min}$ MVPA bouts $(F=6.884, \mathrm{p}=0.028)$. Because physical function variables were skewed, they were further log-transformed. Similar to a previous review, ${ }^{41}$ forced-entry multiple linear regression models were performed for investigating gender differences and the extent to which objectively assessed PA (total PA time, daily MVPA time, daily LPA time, daily step counts and the number of $10 \mathrm{~min}$ MVPA bouts) was associated with physical function after adjusting for potential confounders. Furthermore, we examined the degree of multicollinearity between the studied variables by checking their variance inflation factors (VIFs), with a value above 10 indicating high multicollinearity. ${ }^{42}$ In sensitivity analyses, we performed a stepwise omission of variables with the highest VIF from the regression models to confirm the robustness of our results to the small sample size. R-squared was calculated to evaluate the explanatory power of different models (presented in the online supplementary appendix 1). ${ }^{43}$ We used IBM SPSS V.23.0 for all statistical analyses. The significance level was set at $\mathrm{p}<0.05$.

\section{RESULTS}

\section{Participant characteristics}

Table 1 depicts the basic characteristics of the entire sample stratified by gender. In all, 127 participants (36 older men and 91 older women) were analysed. Their mean age was $70.8 \pm 5.3$ years. Overall, $78.0 \%$ of the participants had an educational level of up to high school, $66.1 \%$ were married, $89.0 \%$ lived with family or others and $96.9 \%$ had part-time jobs. Regarding health behaviours, $5.5 \%$ of the participants were smokers, $7.9 \%$ drank alcohol and $26.0 \%$ had unhealthy diets. The independent t-test showed that, on average, the male participants (mean age $=69.4 \pm 3.8$ years) were younger than their female counterparts (mean age $=71.3 \pm 5.7$ years). The $\chi^{2}$ test showed that older men were more likely to be married and living with others, while older women were more likely to be non-smokers.

\section{Gender differences in total amounts and patterns of objectively assessed PA and physical function}

Table 2 depicts the gender differences in objectively assessed PA and physical function. The independent t-test indicated no difference in accelerometer wear time between older men and women. Regarding the amount and patterns of PA, older men had significantly less daily total PA and LPA and more daily MVPA, step counts and 10 min MVPA bouts than older women. Older men and women performed similarly on each of the physical function tests, but older men had higher handgrip strength than older women (men $=33.2528 \pm 6.517$, women $=21.4281 \pm 3.453, \mathrm{p}<0.0001)$. The mean $\pm \mathrm{SD}$ of accelerometer wear time was 905.744 \pm 109.454 (15.1 hours) $\mathrm{min} /$ day for older men and 925.339 \pm 73.153 (15.4 hours) $\mathrm{min}$ /day for older women.

\section{Multiple linear regression analysis between amounts and patterns of objectively assessed PA and physical function among older men and women}

Table 3 depicts the associations of objectively assessed PA with physical function among older men and women. After adjusting for potential confounders, daily MVPA time was positively related to handgrip strength ( $\beta$ : 0.39 , 95\% CI: $0.12,0.64 ; p=0.004)$ and time taken for the single-leg stance test ( $\beta$ : $0.25,95 \%$ CI: 0.02, $0.49 ; p=0.036$ ) 


\begin{tabular}{|c|c|c|c|c|}
\hline Variables & $\begin{array}{l}\text { Total } \\
\text { sample } \\
(n=127)\end{array}$ & $\begin{array}{l}\text { Older men } \\
(n=36)\end{array}$ & $\begin{array}{l}\text { Older } \\
\text { women } \\
(n=91)\end{array}$ & $P$ value \\
\hline Age $(\mathrm{M} \pm \mathrm{SD})$ & $70.8 \pm 5.3$ & $69.4 \pm 3.8$ & $71.3 \pm 5.7$ & 0.042 \\
\hline \multicolumn{5}{|l|}{ Educational level (\%) } \\
\hline University & 22.0 & 27.8 & 19.8 & \multirow[t]{2}{*}{0.327} \\
\hline Up to high school & 78.0 & 72.2 & 80.2 & \\
\hline \multicolumn{5}{|l|}{ Marital status (\%) } \\
\hline Married & 66.1 & 88.9 & 57.1 & \multirow[t]{2}{*}{0.001} \\
\hline Not married & 33.9 & 11.1 & 42.9 & \\
\hline \multicolumn{5}{|l|}{ Living status (\%) } \\
\hline Living with others & 89.0 & 100 & 84.6 & \multirow[t]{2}{*}{0.013} \\
\hline Living alone & 11.0 & 0 & 15.4 & \\
\hline
\end{tabular}

Employment (\%)

\begin{tabular}{cllll} 
Full-time job & 3.1 & 0 & 4.4 & 0.201 \\
Part-time job & 96.9 & 100 & 95.6 & \\
\hline Smoking (\%) & & & & \\
\hline Yes & 5.5 & 13.9 & 2.2 & 0.009 \\
No & 94.5 & 86.1 & 97.8 & \\
\hline
\end{tabular}

Alcohol drinking habit (\%)

$\begin{array}{lllll}\text { Yes } & 7.9 & 13.9 & 5.5 & 0.113 \\ \text { No } & 92.1 & 86.1 & 94.5 & \end{array}$

Healthy diet (\%)

\begin{tabular}{|c|c|c|c|c|}
\hline Yes & 74.0 & 80.6 & 71.4 & 0.291 \\
\hline No & 26.0 & 19.4 & 28.6 & \\
\hline \multicolumn{5}{|l|}{ Depression (\%) } \\
\hline Yes & 15.0 & 8.3 & 17.6 & \multirow[t]{2}{*}{0.188} \\
\hline No & 85.0 & 91.7 & 82.4 & \\
\hline \multicolumn{5}{|l|}{ Diabetes (\%) } \\
\hline Yes & 18.9 & 22.2 & 17.6 & \multirow[t]{2}{*}{0.547} \\
\hline No & 81.1 & 77.8 & 82.4 & \\
\hline \multicolumn{5}{|l|}{ Hypertension (\%) } \\
\hline Yes & 39.4 & 44.4 & 37.4 & \multirow[t]{2}{*}{0.462} \\
\hline No & 60.6 & 55.6 & 62.6 & \\
\hline \multicolumn{5}{|c|}{ High blood lipid levels (\%) } \\
\hline Yes & 29.9 & 30.6 & 29.7 & \multirow[t]{2}{*}{0.922} \\
\hline No & 70.1 & 69.4 & 70.3 & \\
\hline $\mathrm{BMI}\left(\mathrm{kg} / \mathrm{m}^{2}\right)(\mathrm{M} \pm \mathrm{SD})$ & $24.2 \pm 3.4$ & $24.4 \pm 3.3$ & $24.1 \pm 3.4$ & 0.658 \\
\hline Normal weight (\%) & 52.0 & 50 & 52.7 & \multirow[t]{2}{*}{0.780} \\
\hline Overweight (\%) & 48.0 & 50 & 47.3 & \\
\hline
\end{tabular}

BMI, body mass index.

in older women. The number of 10 min MVPA bouts was also positively associated with handgrip strength $(\beta: 0.27$, 95\% CI: 0.001, 0.53; $\mathrm{p}=0.049$ ) in older women. Furthermore, daily step counts were positively related to handgrip strength ( $\beta$ : 0.46, 95\% CI: 0.12, 0.78; $\mathrm{p}=0.009)$ and time on the 5 -metre walk test ( $\beta$ : $-0.31,95 \%$ CI: $-0.57,-0.001$; $\mathrm{p}=0.049$ ) in older women. Among older men, none of the variables of the objectively assessed PA patterns was significantly associated with physical function outcomes. However, there were 36 men and 91 women in this study; therefore, sampling bias and its distribution might have underestimated the present results.

Additionally, the results of the sensitivity analyses of the association between objectively assessed PA and physical function among older men and women are presented in the online supplementary appendix 1 . The stepwiseomitted variables showing the highest VIF, similar results across different adjusted models and the final adjusted model with the largest explanatory power constituted the main analyses.

\section{DISCUSSION}

This study on Taiwanese older adults aged 65-87 years and living in the community aimed to assess various aspects of PA (total PA, LPA, MVPA, number of 10 min MVPA bouts and walking steps) using objective measures of physical function. The main finding of this study is that more time spent on daily MVPA or at least 10 min MVPA bouts were associated positively with higher handgrip strength among older women. More time spent on daily MVPA was also associated with single-leg balance capacity after adjustment for multiple confounding variables, including accelerometer wear time and sedentary time. Notably, a higher daily step count was related to better handgrip strength and gait speed among older women. Previous studies have shown that poor physical function is predictive of disability, ${ }^{44}$ falls $^{2}$ and premature death ${ }^{33}$ among older adults. These findings may be critical in informing health-promotion professionals and practitioners, as well as encouraging PA and preventing the deterioration of physical function, especially among older women.

A previous study indicated that PA bouts of at least $10 \mathrm{~min}$ are related to lower risks of obesity and functional limitations among older adults. ${ }^{45}$ Nevertheless, there is a lack of data showing whether physical function benefits from increased bouts of 10 min MVPA or whether it is the total amount of PA that is critical or the pattern in which it is accumulated. Our study provides substantial evidence for the finding that accumulated daily MVPA time is associated with improved upper body strength and standing balance performance. Concurrently, more prolonged and continuous MVPA bouts $(\geq 10 \mathrm{~min})$ were also associated with better handgrip strength, but not as strongly as time spent on MVPA. This finding is consistent with previous studies ${ }^{9} 101823$ and supports current PA guidelines for older adults suggesting that aerobic MVPA should be performed in bouts of not less than $10 \mathrm{~min}$ to gain health benefits. ${ }^{46}$ This study implies that accumulated long MVPA bouts and daily MVPA time may both be significant in the maintenance of older women's physical function, specifically their handgrip strength. Our result is also consistent with previous studies using a pedometer. ${ }^{56}$ We found that triaxial accelerometer-assessed daily step counts were positively related to handgrip strength and mobility (walking speed) among older women, after 
Table 2 Total amounts and patterns of objectively assessed physical activity and physical function among older men and women

\begin{tabular}{|c|c|c|c|}
\hline & Older men $(n=36)$ & Older women $(n=91)$ & \\
\hline & M (SD) & M (SD) & $P$ value \\
\hline \multicolumn{4}{|l|}{ Accelerometer variables } \\
\hline Total PA time (min/day) & 292.007 (90.338) & $326.434(79.592)$ & 0.037 \\
\hline Daily LPA time (min/day) & $255.270(84.981)$ & 306.907 (73.449) & 0.001 \\
\hline Daily step counts (steps/day) & $8408.938(4051.721)$ & 7078.991 (3034.208) & 0.046 \\
\hline No. of 10 min MVPA bouts (no./day) & $1.756(1.482)$ & $1.145(1.042)$ & 0.028 \\
\hline \multicolumn{4}{|l|}{ Physical function } \\
\hline Handgrip strength (kg) & 33.253 (6.517) & 21.428 (3.453) & $<0.001$ \\
\hline Single-leg stance test (s) & $39.577(23.760)$ & $34.7460(23.028)$ & 0.296 \\
\hline Sit-to-stand test & $7.541(2.160)$ & $7.448(2.698)$ & 0.855 \\
\hline
\end{tabular}

$10 \mathrm{~min}$ MVPA bouts were defined as periods of at least $10 \mathrm{~min}$ with $\geq 2020$ counts $/ \mathrm{min}$. $\mathrm{P}<0.05$.

LPA, light physical activity; MVPA, moderate-to-vigorous physical activity; PA, physical activity.

adjusting for wear time and sedentary time. This suggests the importance of accumulating steps in everyday life in this population. In this study, the mean step count among older women was 7078 steps/day (median, 6991 steps/ day) (table 2). This supports previous reviews, indicating that approximately $7000-8000$ steps/day may reap health benefits. ${ }^{48}$ According to a previous study, the risk of mortality progressively decreased before levelling at approximately 7500 steps / day. ${ }^{15}$ Therefore, as mentioned previously, our findings may have significant implications for policymakers or PA intervention designers regarding the development of effective strategies to improve specific aspects of PA to prevent physical function decline in older women.

Another important finding of our study is that there are gender differences in the relationship between accelerometer-assessed PA and physical performance, which is consistent with previous studies. ${ }^{1723}$ This study showed that each PA pattern was not related to each physical function test in older men. Several possible reasons can explain these differences. First, older men and women in Taiwan have distinct gender roles and lifestyle patterns. For example, more often than not, older women rather than men take on household and family-related responsibilities, which may contribute to several short bouts of PA in daily life. These fragmented daily PAs are important for physical functional performance in older adults. ${ }^{24} 25$ Hence, our results showed that older women tended to have lifestyle patterns involving extended periods of LPA, less daily MVPA time and lower long-bout MVPA (table 2) than older men. Second, this difference may be explained by the fact that older women have less skeletal muscle mass and density compared with older men. ${ }^{49}$ Evidence from a large sample indicated that the prevalence of disability increased with age, but older women experienced a higher rate of disability than older men across all age groups. ${ }^{44}$ Although the association between PA and physical function may be stronger in older women than in older men, the relationship between daily MVPA time and single-leg stance test seems similar among them. For example, the association between daily MVPA time and single-leg stance was 0.23 and 0.25 for older men and women, respectively (table 3 ). If the sample had included more older men in the study to match the sample size of older women $(\mathrm{n}=91)$, then the $95 \%$ CI would have been $0.23 \pm 1.96 *(0.26-(-0.15)) /(3.92 * \operatorname{sqrt}(91 / 36))=(0.10$, $0.36)$ and would display a significant $p$ value $(<0.05)$. Simply using $p$ values to infer the relationship between PA and physical functions may have underestimated the results of older men, especially in a small sample size. Thus, future studies are warranted to confirm these results.

The prime strength of this study is that it is the first in Taiwan to examine a comprehensive range of objectively assessed PA patterns, from daily time spent on total PA, LPA, MVPA, MVPA bouts of at least $10 \mathrm{~min}$ and daily walking steps to gender differences and their associations with physical function. Few studies have concurrently considered these factors in samples of older Asian adults. Moreover, our study goes beyond existing studies, which separately investigated total PA, MVPA or LPA volumes, ${ }^{13} 2345$ only examining lower-limb performance outcomes, ${ }^{13}{ }^{19}$ rather than different types of PA of specific intensities, or did not examine the association of the frequency of long-bout MVPA with multiple physical function components (mobility, upper and lower-limb 


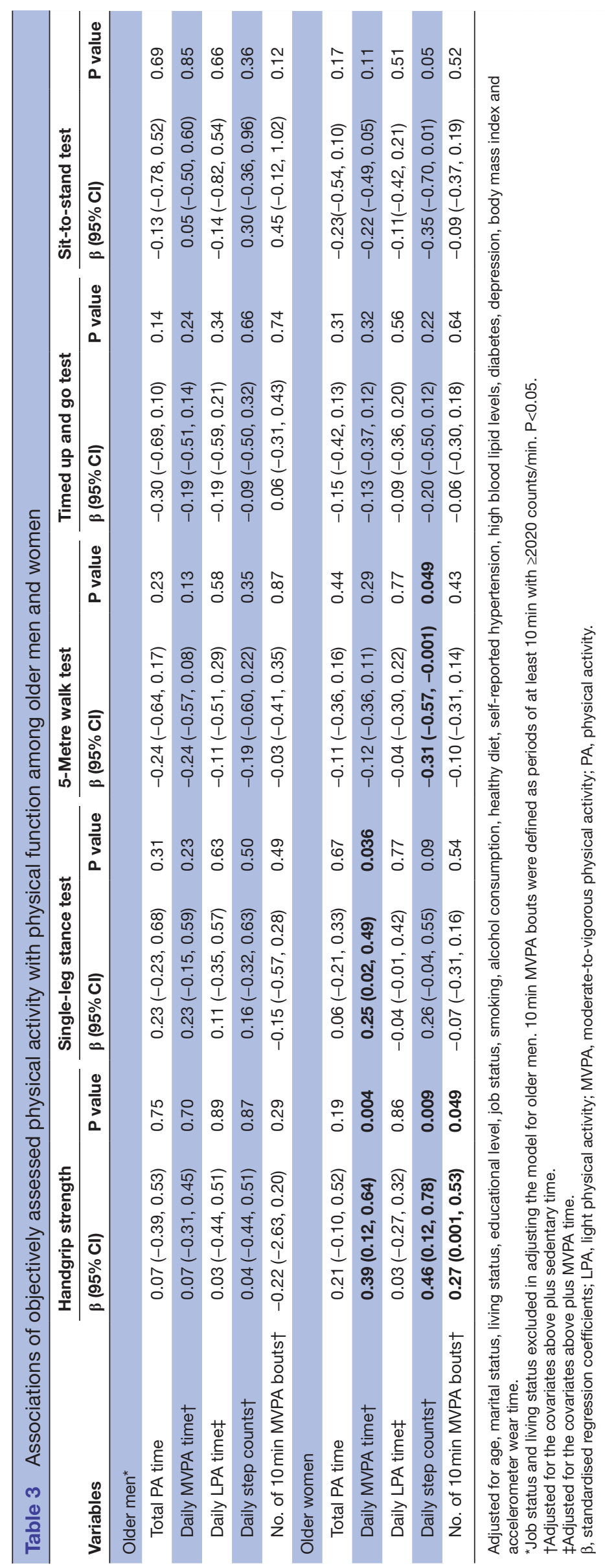


strength and balance). Moreover, unlike previous studies, our study adjusted for several general confounding factors, such as sociodemographic factors and mental health (depression status). Likewise, accelerometerrelated confounders were also included (wear time and sedentary time). However, other potential confounders, such as frailty status, which could have contributed to some associations, were not considered.

This study has several limitations. First, the crosssectional design could limit causal inferences regarding the relationship between PA and physical function. Second, although this study elicits walking step counts generated from wearable devices, the previous study mentioned that the ActiGraph GT3X+ device might underestimate the steps in older adults, especially with slower gait speeds. ${ }^{50}$ Thus, a direct comparison of steps measured by different devices may be appropriate. Third, the number of male participants was low. A well-designed large-scale representative sample is needed to assess PA patterns associated with specific physical function benefits in older men. Moreover, cultural norms and self-esteem could explain this gap. Engagement in neighbourhood PA groups is more positive for older women than older men, which discourages Taiwanese older men from participating in PA or health-related programmes. Fourth, due to a potential selection bias, caution should be exercised when interpreting the results. This study also used convenience sampling to select participants that were relatively healthy and, therefore, more willing to participate than others in this population. Consequently, the findings of our study cannot represent the general older population in Taiwan.

\section{CONCLUSIONS}

The present study suggests that among older women, spending time on daily MVPA, particularly at least $10 \mathrm{~min}$ bouts of MVPA and daily walking steps is independently associated with better handgrip strength performance regardless of sedentary time, accelerometer wear time and other confounders. Our findings also suggest that among older women, daily MVPA time and accumulated daily walking steps are likely to improve standing balance and mobility, respectively, regardless of sedentary time, accelerometer wear time and other confounders. Therefore, promoting daily MVPA, long bouts of MVPA and daily walking steps among older women should be prioritised to improve physical function capacity and independence.

\footnotetext{
Author affiliations

${ }^{1}$ Graduate Institute of Sport Pedagogy, University of Taipei, Taipei, Taiwan ${ }^{2}$ Department of Health Promotion and Health Education, National Taiwan Normal University, Taipei, Taiwan

${ }^{3}$ Health Convergence Medicine Laboratory, Biomedical Research Institute, Pusan National University Hospital, Busan, Republic of Korea

${ }^{4}$ Institute of Convergence Bio-Health, Dong-A University, Busan, Republic of Korea ${ }^{5}$ Department of Health Care Science, Dong-A University, Busan, Republic of Korea
}

Contributors $\mathrm{M}-\mathrm{CH}, \mathrm{C}-\mathrm{CC}$ and $\mathrm{YL}$ contributed to conceptualisation; $\mathrm{M}-\mathrm{CH}$ and C$\mathrm{CC}$ contributed to data curation; $\mathrm{M}-\mathrm{CH}, \mathrm{RR}$ and $\mathrm{C}-\mathrm{CC}$ contributed to formal analysis $\mathrm{M}-\mathrm{CH}, \mathrm{J}-\mathrm{HP}$ and $\mathrm{H}-\mathrm{TP}$ contributed to funding acquisition; $\mathrm{M}-\mathrm{CH}$ and RR contributed to investigation; $\mathrm{M}-\mathrm{CH}, \mathrm{C}-\mathrm{CC}$ and $\mathrm{YL}$ contributed to methodology; $\mathrm{M}-\mathrm{CH}, \mathrm{J}-\mathrm{HP}$ and $\mathrm{YL}$ contributed to project administration; $\mathrm{M}-\mathrm{CH}, \mathrm{J}-\mathrm{HP}$ and $\mathrm{H}-\mathrm{TP}$ contributed to resources; M-CH and RR contributed to software; J-HP, H-TP and YL contributed to supervision; $\mathrm{M}-\mathrm{CH}, \mathrm{C}-\mathrm{CC}$ and $\mathrm{J}-\mathrm{HP}$ contributed to validation; $\mathrm{M}-\mathrm{CH}$ contributed to visualisation; $\mathrm{M}-\mathrm{CH}, \mathrm{RR}$ and $\mathrm{C}-\mathrm{CC}$ contributed to writing - original draft; $\mathrm{M}-\mathrm{CH}$, $\mathrm{C}-\mathrm{CC}, \mathrm{J}-\mathrm{HP}, \mathrm{H}-\mathrm{TP}$ and $\mathrm{YL}$ contributed to writing — review and editing. All authors approved the final version.

Funding This work was supported by the Ministry of Science and Technology of Taiwan grant number MOST 106-2410 H-003-144-MY2. This research was supported by a grant of the Korea Health Technology R\&D Project through the Korea Health Industry Development Institute (KHIDI), funded by the Ministry of Health \& Welfare, Republic of Korea (grant number : Hl15C1529). This work was supported by the Ministry of Education of the Republic of Korea and the National Research Foundation of Korea(NRF-2018S1A5A2A03037691).

Competing interests None declared.

Patient consent for publication Not required.

Ethics approval The Research Ethics Committee of the National Taiwan Normal University approved this study in 2017 (REC number: 201711HM003).

Provenance and peer review Not commissioned; externally peer reviewed.

Data availability statement All data relevant to the study are included in the article or uploaded as supplementary information.

Open access This is an open access article distributed in accordance with the Creative Commons Attribution Non Commercial (CC BY-NC 4.0) license, which permits others to distribute, remix, adapt, build upon this work non-commercially, and license their derivative works on different terms, provided the original work is properly cited, appropriate credit is given, any changes made indicated, and the use is non-commercial. See: http://creativecommons.org/licenses/by-nc/4.0/.

\section{ORCID iDs}

Ming-Chun Hsueh http://orcid.org/0000-0001-6723-9487

Ru Rutherford http://orcid.org/0000-0003-1277-4479

Yung Liao http://orcid.org/0000-0002-4401-8275

\section{REFERENCES}

1 World Health Organization. What is healthy ageing? 2019. Available: https://www.who.int/ageing/healthy-ageing/en/

2 Smee DJ, Anson JM, Waddington GS, et al. Association between physical functionality and falls risk in Community-Living older adults. Curr Gerontol Geriatr Res 2012;2012:864516.

3 Department of Statistics Mol. Monthly Bulletin of interior statistics, 2018.

4 Welfare MoHa. Ten-Year long-term care program in Taiwan, 2018.

5 de Melo LL, Menec VH, Ready AE. Relationship of functional fitness with daily steps in community-dwelling older adults. $J$ Geriatr Phys Ther 2014;37:116-20.

6 Duncan MJ, Minatto G, Wright SL. Dose-response between pedometer assessed physical activity, functional fitness, and fatness in healthy adults aged 50-80 years. Am J Hum Biol 2016;28:890-4.

7 World Health Organization. Global recommendations on physical activity for health. Geneva: World Health Organization, 2010. https:// apps.who.int/iris/bitstream/handle/10665/44399/9789241599979 eng.pdf;jsessionid=B32E132C1D7BA81A6D97FB1E382C7039? sequence $=1$

8 Loprinzi PD, Lee H, Cardinal BJ. Evidence to support including lifestyle Light-intensity recommendations in physical activity guidelines for older adults. Am J Health Promot 2015;29:277-84.

9 Cooper AJM, Simmons RK, Kuh D, et al. Physical activity, sedentary time and physical capability in early old age: British birth cohort study. PLoS One 2015;10:e0126465.

10 Jantunen $\mathrm{H}$, Wasenius $\mathrm{N}$, Salonen MK, et al. Objectively measured physical activity and physical performance in old age. Age Ageing 2017:46:232-7.

11 Hallal PC, Andersen LB, Bull FC, et al. Global physical activity levels: surveillance progress, pitfalls, and prospects. Lancet 2012;380:247-57.

12 White DK, Lee J, Song J, et al. Potential functional benefit from light intensity physical activity in knee osteoarthritis. Am J Prev Med 2017;53:689-96 
13 Osuka Y, Yabushita N, Kim M, et al. Association between habitual Light-intensity physical activity and lower-extremity performance: a cross-sectional study of community-dwelling older Japanese adults. Geriatr Gerontol Int 2015;15:268-75.

14 Saint-Maurice PF, Troiano RP, Matthews CE, et al. Moderate-toVigorous physical activity and all-cause mortality: do bouts matter? $J$ Am Heart Assoc 2018;7:e007678.

15 Lee I-M, Shiroma EJ, Kamada M, et al. Association of step volume and intensity with all-cause mortality in older women. JAMA Intern Med 2019. doi:10.1001/jamainternmed.2019.0899. [Epub ahead of print: 29 May 2019]

16 Saint-Maurice PF, Troiano RP, Bassett DR, et al. Association of daily step count and step intensity with mortality among US adults. JAMA 2020;323:1151-60.

17 Storti KL, Pettee KK, Brach JS, et al. Gait speed and step-count monitor accuracy in community-dwelling older adults. Med Sci Sports Exerc 2008;40:59-64.

18 Hrubeniuk TJ, Senechal M, Mayo A, et al. Association between physical function and various patterns of physical activity in older adults: a cross-sectional analysis. Aging Clin Exp Res 2019.

19 Reid N, Daly RM, Winkler EAH, et al. Associations of MonitorAssessed activity with performance-based physical function. PLoS One 2016;11:e0153398.

20 Ku P-W, Steptoe A, Liao Y, et al. A threshold of Objectively-Assessed daily sedentary time for all-cause mortality in older adults: a meta-regression of prospective cohort studies. J Clin Med 2019;8. doi:10.3390/jcm8040564. [Epub ahead of print: 25 Apr 2019].

21 Lee I-M, Shiroma EJ, Evenson KR, et al. Accelerometer-Measured physical activity and sedentary behavior in relation to all-cause mortality: the women's health study. Circulation 2018;137:203-5.

22 Jefferis BJ, Parsons TJ, Sartini C, et al. Objectively measured physical activity, sedentary behaviour and all-cause mortality in older men: does volume of activity matter more than pattern of accumulation? Br J Sports Med 2019;53:1013-20.

23 Santos DA, Silva AM, Baptista F, et al. Sedentary behavior and physical activity are independently related to functional fitness in older adults. Exp Gerontol 2012;47:908-12.

24 Kuo P, Zipunnikov V, Di J, et al. Fragmentation of physical activity is strongly associated with gait speed and fatigability. Innov Aging 2017;1:252.

25 Schrack JA, Kuo P-L, Wanigatunga AA, et al. Active-to-Sedentary behavior transitions, fatigability, and physical functioning in older adults. J Gerontol A Biol Sci Med Sci 2019;74:560-7.

26 Chang S-H, Hsueh M-C, Liao Y. Personal and behavioral correlates of total and domain-specific sedentary behaviors in older Taiwanese adults. BMC Geriatr 2018;18:294.

27 Chen B-I, Hsueh M-C, Rutherford R, et al. The associations between neighborhood walkability attributes and objectively measured physical activity in older adults. PLoS One 2019;14:e0222268.

28 Aguilar-Farías N, Brown WJ, Peeters GMEEG. ActiGraph GT3X+ cutpoints for identifying sedentary behaviour in older adults in free-living environments. J Sci Med Sport 2014;17:293-9.

29 Evenson KR, Buchner DM, Morland KB. Objective measurement of physical activity and sedentary behavior among US adults aged 60 years or older. Prev Chronic Dis 2012;9:E26.

30 Meredith-Jones K, Williams S, Galland B, et al. $24 \mathrm{~h}$ Accelerometry: impact of sleep-screening methods on estimates of sedentary behaviour and physical activity while awake. J Sports Sci 2016;34:679-85.
31 Troiano RP. Large-scale applications of accelerometers: new frontiers and new questions. Med Sci Sports Exerc 2007;39:1501.

32 Piercy KL, Troiano RP, Ballard RM, et al. The physical activity guidelines for Americans. JAMA 2018;320:2020-8.

33 Cooper R, Kuh D, Hardy R, et al. Objectively measured physical capability levels and mortality: systematic review and meta-analysis. BMJ 2010;341:c4467.

34 Abizanda P, Navarro JL, García-Tomás MI, et al. Validity and usefulness of hand-held dynamometry for measuring muscle strength in community-dwelling older persons. Arch Gerontol Geriatr 2012;54:21-7.

35 Taekema DG, Gussekloo J, Maier AB, et al. Handgrip strength as a predictor of functional, psychological and social health. A prospective population-based study among the oldest old. Age Ageing 2010;39:331-7.

36 Izawa KP, Watanabe S, Oka K. Relationship of thresholds of physical performance to nutritional status in older hospitalized male cardiac patients. Geriatr Gerontol Int 2015;15:189-95.

37 Lusardi MM, Pellecchia GL, Schulman M. Functional performance in community living older adults. J Geriatr Phys Ther 2003;26:14-22.

38 Podsiadlo D, Richardson S. The timed "Up \& Go": a test of basic functional mobility for frail elderly persons. J Am Geriatr Soc 1991;39:142-8.

39 Buatois S, Miljkovic D, Manckoundia P, et al. Five times sit to stand test is a predictor of recurrent falls in healthy community-living subjects aged 65 and older. J Am Geriatr Soc 2008:56:1575-7.

40 WHO Expert Consultation. Appropriate body-mass index for Asian populations and its implications for policy and intervention strategies. Lancet 2004;363:157-63.

41 Pourhoseingholi MA, Baghestani AR, Vahedi M. How to control confounding effects by statistical analysis. Gastroenterol Hepatol Bed Bench 2012;5:79-83.

42 James G, Witten D, Hastie T, et al. An introduction to statistical learning. Springer, 2013.

43 Rawlings JO, Pantula SG, Dickey DA. Applied regression analysis: a research tool. Springer Science \& Business Media, 2001.

44 Mayhew AJ, Griffith LE, Gilsing A, et al. The association between self-reported and performance-based physical function with activities of daily living disability in the Canadian longitudinal study on aging. $J$ Gerontol A Biol Sci Med Sci 2019.

45 Gennuso KP, Gangnon RE, Matthews CE, et al. Sedentary behavior, physical activity, and markers of health in older adults. Med Sci Sports Exerc 2013;45:1493-500.

46 Nelson ME, Rejeski WJ, Blair SN, et al. Physical activity and public health in older adults: recommendation from the American College of sports medicine and the American heart association. Med Sci Sports Exerc 2007;39:1435-45.

47 Tudor-Locke C, Craig CL, Aoyagi Y, et al. How many steps/day are enough? For older adults and special populations. Int $J$ Behav Nutr Phys Act 2011:8:80.

48 Chen ST CL, PW K. Daily steps and health in adults: should we walk 10000 steps per day for optimal well-being? Taiwan J Public Health 2020;39:17-26.

49 Jankowski CM, Gozansky WS, Van Pelt RE, et al. Relative contributions of adiposity and muscularity to physical function in community-dwelling older adults. Obesity 2008;16:1039-44.

50 Kuo P-L, Urbanek JK, Schrack JA. Age-Related bias in total step count recorded by wearable devices. JAMA Intern Med 2019;179:1602 